\title{
The protective effects of dexmedetomidine on hepatic ischemia reperfusion injury
}

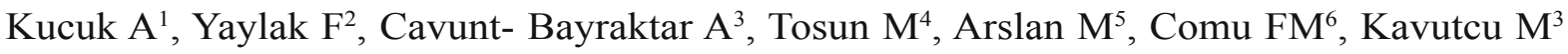 \\ Department of Physiology, Dumlupinar University, Medical Faculty, Kutahya, Turkey. kucukaysegul@hotmail.com
}

\begin{abstract}
Objective: The aim of this study was to evaluate the effect of dexmedetomidine $(100 \mu \mathrm{g} / \mathrm{kg}$-ip) on liver ischemia and reperfusion $(I / R)$ in rats.

Methods: Twenty-four Wistar Albino rats were separated into three groups as control (C), ischemia-reperfusion injury (I/R) and dexmedetomidine group (I/R-D). Ischemia was induced with portal clampage for 45 minutes and reperfusion period was 45 minutes after declampage. Group I/R-D was received dexmedetomidine $100 \mu \mathrm{g} /$ kg i.p. 30 min before portal clampage. Thiobarbutiric Acid-Reactive Substances (TBARS), glutathioneS-transferase (GST), superoxide dismutase (SOD), Catalase (CAT), and Paraoxonase 1 (PON-1) were investigated in blood samples. Also HSP60 and p53-positive hepatocytes were counted under ImageJ image analysis program. Results: All parameters, except GST levels, were significant between the groups $(p<0.05)$. Although HSP60 expression was significantly increased between I/R, I/R-D and $C$ groups there were no significant differences between I/R-D and C ( $p=0.443)$. On the other hand, $p 53$ expression was also significantly increased between I/R, I/R-D and $C$ groups At the same time, there were no significant differences between I/R-D and $C$ groups $(p=0.354)$.

Conclusion: All the results suggest that dexmedetomidine has beneficial effects on liver ischemia/reperfusion stress (Tab. 1, Fig. 2, Ref. 49). Text in PDF www.elis.sk.

Key words: dexmedetomidine, ischemia reperfusion, HSP60, p53, rat.
\end{abstract}

Hepatic ischemia - reperfusion ( $\mathrm{I} / \mathrm{R})$ injury is a common problem in trauma, hepatic surgery, and transplantation. Previous clinical and experimental studies investigated several aspects of this clinical entity (1-4). Hepatic I/R injury is a result of a complex of different mechanisms including both cellular and molecular elements such as leukocytes, TNF $\alpha, \mathrm{NO}, \mathrm{NFkaB}$, and the others (2). Oxidative stress, free radical formation and lipid peroxidation play important roles in the development of I/R injury (5).

Oxidative stress occurs particularly in reperfusion after ischemia. During this process proinflammatory cytokines are synthezised and cell adhesion molecules are activated. Thus the inflammatory response is increased by oxidative stress. The antioxidant

${ }^{1}$ Department of Physiology, Dumlupinar University Medical Faculty, Kutahya, Turkey, ${ }^{2}$ Department of General Surgery, Dumlupinar University Medical Faculty, Kutahya, Turkey, ${ }^{3}$ Department of Medical Biochemistry, Gazi University Medical Faculty, Ankara, Turkey, ${ }^{4}$ Afyon Kocatepe University Medical Faculty, Department of HistologyEmbryology, Afyonkarahisar, Turkey, ${ }^{5}$ Department of Anesthesiology and Reamination, Gazi University Medical Faculty, Ankara, Turkey, and ${ }^{6}$ Kirikkale University Medical Faculty, Physiology Department, Kirikkale, Turkey

Addressforcorrespondence: A. Kucuk, Dumlupinar University, Medical Faculty, Physiology Department, Tavsanliroad, 10.km Kutahya, Turkey. Phone: +90.2742652031

Acknowledgement: The abstract of our manuscript was accepted for poster presentation at the Joint Congress of FEPS and Turkish Society of Physiological Sciences, Turkey in 2011. system has an important role in protection from the damage of oxidative stress (5-9).

Malondialdehyde (MDA) is an intermediate product of lipid peroxidation and is used for assessment of tissue injury attributable to free radicals produced by ischemia/ reperfusion (10).

Different apoptotic pathway regulators including p53 gene which is one of the most important tumor suppressor genes may play important roles to protect tissue from irreversible DNA damage (11).

Dexmedetomidine, a selective and potent $\alpha 2$ - adrenoceptor agonist, was approved by the U.S. Food and Drug Administration in 1999 for sedation of patients hospitalized in intensive care settings. Since then, a growing number of research articles have emerged reporting other possible indications such as regional and general anesthesia $(12,13)$. Dexmedetomidine was reported to be effective in protecting against focal ischemia in rabbits, cardiac IR injury in rats, kidney IR injury in rats, and incomplete forebrain ischemia in rats (14-17). Despite its increased clinical use, many times in critically ill patients, the effect of dexmedetomidine on liver IR injury has not been yet investigated (18).

The present study was therefore designed to evaluate the effectiveness of dexmedetomidine in an established in vivo rat model of hepatic ischemia/reperfusion (I/R) injury and explain the potential mechanisms involved in any beneficial effect with different parameters such as p53 related apoptosis, HSP60 expressions and oxidative stress parameters such as Thiobarbutiric Acid-Reactive Substances (TBARS) levels, glutathioneS-transferase (GST), 

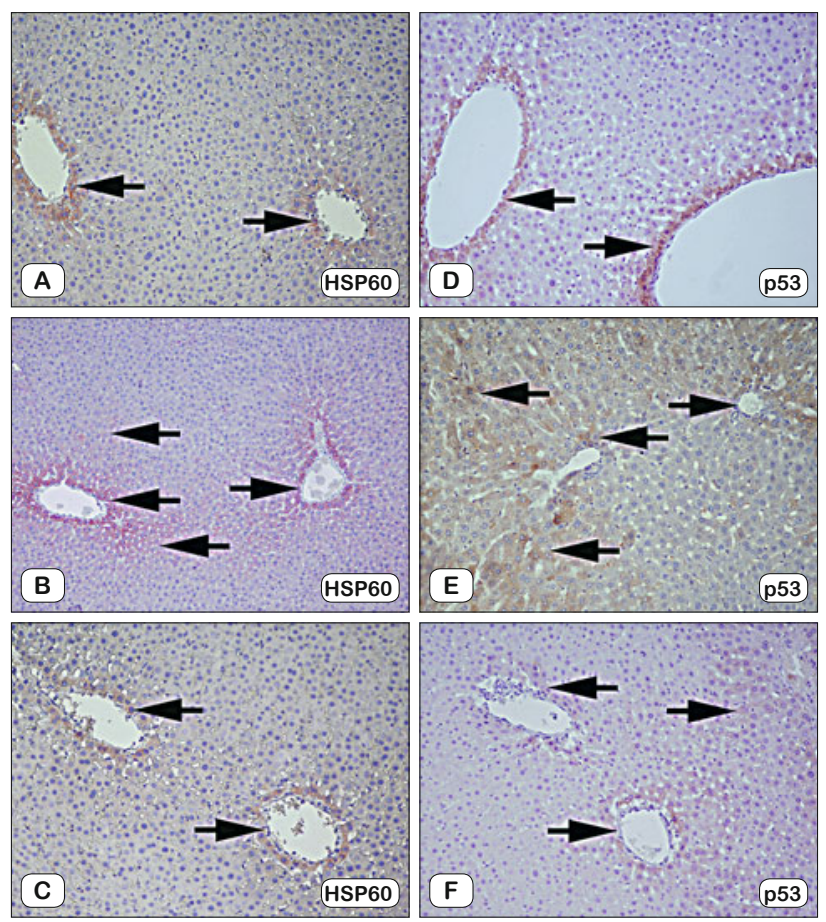

Fig. 1. Expressions of HSP60 (A to C) and p53 (D to E) in liver in all groups. Arrows: Immunopositive cells. All magnifications are x200.

superoxide dismutase (SOD), catalase (CAT), and paraoxonase 1 (PON-1) activities (Fig. 1).

\section{Materials and methods}

\section{Animals and experimental protocol}

The experiments were performed in adherence to National Institutes of Health guidelines on the use of experimental animals. Twenty-four male, Wistar rats, weighing from 275 to $350 \mathrm{~g}$, were housed at constant temperature with $12 / 12 \mathrm{~h}$ periods of light and dark exposure. Animals were allowed access to standard rat chow and water ad libitum during an acclimation period of at least 5 days prior to use in these experiments. The approval of Institutional Ethics Committee was obtained. The experiments were performed in the Animal Experimental Laboratory of the Physiology Department in Kirikkale University.

Rats were anesthetized with intramuscular ketamine $100 \mathrm{mg}$ per kg. The chest and abdomen were shaved and each animal was fixed in a supine position on the operating table. The abdomen was cleaned with $1 \%$ polyvinyl iodine and when dry, the operating field was covered with a sterile drape and median laparotomy was performed. There were three experimental groups (Group C (Control; $\mathrm{n}=8$ ), Group I/R (ischemia-reperfusion, $\mathrm{n}=8$ ), and Group I/R-D (I/R-Dexmedetomidine; $\mathrm{n}=8$ ). Precedex $100 \mu \mathrm{g}, 2 \mathrm{ml}\left(\right.$ Abbott $^{\mathbb{R}}$, Abbott Laboratory, North Chicago, Illinois, USA) was administrated via intraperitoneal route 30 minutes before clampage (19).

Sham operation was performed on the rats in Group C. The sham operation consisted of mobilization of the hepatic pedicle only. The rats in this group were sacrificed 90 min after the procedure. Hepatic I/R injury was induced in Groups I/R and I/R-D, respectively by hepatic pedicle clampage using a vascular clamp as in the previous study of Yaylak et al (3). After an ischemia period of $45 \mathrm{~min}$, the vascular clamp was removed. A reperfusion period was maintained for $45 \mathrm{~min}$.

All the rats were given ketamine $100 \mathrm{mg} \cdot \mathrm{kg}^{-1}$ intraperitoneally and intracardiac blood samples were obtained.

\section{Biochemical analysis}

The liver tissues were first washed with cold deionized water to discard blood contamination and then homogenized in a homogenizator (Heidolph DIAX900) at 3,000 rpm for $3 \mathrm{~min}$. After centrifugation at $10,000 \mathrm{xg}$ for $10 \mathrm{~min}$. the upper clear layer was taken. Protein and TBARS amounts were measured as described by Lowry et al. (20) and Van Ye et al (21) respectively in this fraction. Part of the homogenate was extracted in ethanol/chloroform mixture $(5 / 3 \mathrm{v} / \mathrm{v})$ to discard the lipid fraction, which caused interferences in the activity measurements of T-SOD, CAT and GST activities. After centrifugation at $10,000 \mathrm{x}$ g for $60 \mathrm{~min}$, the upper clear layer was removed and used for the T-SOD, CAT, GST analyses.

In the upper clear layer, T-SOD, CAT, GST and PON 1 enzyme activities were measured as described Durak et al (22), Aebi (23) and Habig et al (24), methods respectively. One unit of SOD activity was defined as the enzyme protein amount causing $50 \%$ inhibition in $\mathrm{NBTH}_{2}$ reduction rate, and the results were expressed in $\mathrm{U} / \mathrm{mg}$ protein. The CAT activity method is based on the measurement of absorbance decrease due to $\mathrm{H}_{2} \mathrm{O}_{2}$ consumption at 240 $\mathrm{nm}$. The GST activity method is based on the measurement of absorbance changes at $340 \mathrm{~nm}$ due to formation of GSH-CDNB complex. PON1 activity toward paraoxon was assessed by adding samples to $2 \mathrm{~mL}$ Tris/ $\mathrm{HCl}$ buffer containing $\mathrm{CaCl}_{2}$, paraoxon (O,O-diethyl-O-p- nitrophenylphosphate), and $\mathrm{NaCl}$. The rate of generation of $\mathrm{p}$-nitrophenol was determined at $405 \mathrm{~nm}$ and $25^{\circ} \mathrm{C}$ in a spectrophotometer. Increases in absorbance were recorded at 30 -sec intervals during $5 \mathrm{~min}$ after $30 \mathrm{sec}$ of initial pre-incubation. The enzymatic activity was calculated from molar extinction coefficient (17,000 L/mol.cm).

TBARS assay was carried out using the thiobarbituric acid method and the results were given in $\mathrm{nmol} / \mathrm{mg}$ protein. All the procedures were performed at $4{ }^{\circ} \mathrm{C}$ throughout the experiment.

\section{Histopathological evaluation}

All the specimens were fixed in $10 \%$ neutral formalin and processed with classic histologic method. Several $4 \mu$ sections obtained from these specimens were mounted on poly-L-lysinecoated slides. All the slides were immunohistochemically stained with p53 and HSP60 for detection genome destruction and tissue stress respectively.

HSP60 and p53 positive hepatocytes were counted under ImageJ Image analysis program. The immunopositive cells in 5 different areas in each slide under x 20 objective magnification were counted and immunoreactivity was calculated using with HSCORE 


\section{Liver blood flow measurement}

Liver blood flows were recorded. Blood flow measurements were conducted by placing and fixing the probe on the tissue by a laser Doppler microvascular perfusion monitor (OxyLab LDF; Oxford Optronix Limited, Oxford, UK).

\section{Statistical analysis}

Statistical Package for the Social Sciences (SPSS, Chicago, IL, USA) 12.0 program was used for statistical analysis. Variations in liver tissue oxidative state parameters, liver blood flow, and histopathological evaluation between study groups were assessed by using Kruskal-Wallis test. Bonferroni-adjusted Mann-Whitney U test was used after significant Kruskal-Wallis to determine which group differs from the other. Results were expressed as mean \pm standart deviation (Mean $\pm \mathrm{SD}$ ). Statistical significance was set at a $\mathrm{p}<0.05$ for all analyses.

\section{Results}

In the biochemical evaluation, all parameters, except GST levels, were significant between the groups $(p<0.05)$.

SOD activities and TBARS levels were also higher in I/R group than in the other groups (SOD: Control Group- IR Group $\mathrm{p}=0.007$, IR Group- IRD Group $\mathrm{p}=0.047$; TBARS: Control Group- IR Group $p=0.028$, IR Group- IRD Group $p=0.011$ ) (Tab. 1). However, dexmedetomidine treatment in I/R-D group resulted with SOD activities and TBARS levels similar to those in the control group, (Tab. 1).

Similarly, PON-1 activity was also higher in I/R group than in other groups (Control Group- IR Group $p=0.032$, IR GroupIRD Group $\mathrm{p}=0.016)($ Tab. 1).

CAT activity was also higher in Control Group than in the other groups (Control Group- IR Group p $=0.002$, Control Group- IRD Group $\mathrm{p}=0.036)($ Tab. 1).

Although HSP60 expression was significantly increased among I/R, I/R-D and C groups there were no significant differences between $\mathrm{I} / \mathrm{R}-\mathrm{D}$ and $\mathrm{C}(\mathrm{p}=0.443)$. On the other hand, $\mathrm{p} 53$ expression was also significantly increased among $I / R, I / R-D$ and $\mathrm{C}$ groups but there were no significant differences between I/R-D and $\mathrm{C}$ groups $(\mathrm{p}=0.354)$.

In the liver blood blow measurement; it was detected that when compared with after ischemia period in Group IR, the liver blood flow in Group IRD was significantly decreased (IR Group - IRD Group $\mathrm{p}=0.028$ ) (Fig. 2). In addition, in the period after

Tab. 1. Biohemical parameters in rat liver tissues.

\begin{tabular}{lcccc}
\hline $\begin{array}{l}\text { Groups and } \\
\text { biochemical } \\
\text { parameters }\end{array}$ & $\begin{array}{c}\text { Group C } \\
(\mathrm{n}=8)\end{array}$ & $\begin{array}{c}\text { Group I/R } \\
(\mathrm{n}=8)\end{array}$ & $\begin{array}{c}\text { Group I/R+D } \\
(\mathrm{n}=8)\end{array}$ & $\mathrm{p}$ \\
\hline TBARS & $2.13 \pm 0.90$ & $3.55 \pm 1.30^{*}$ & $1.81 \pm 0.38^{\&}$ & 0.019 \\
GST & $1.19 \pm 0.48$ & $1.01 \pm 0.57$ & $1.43 \pm 0.66$ & 0.272 \\
SOD & $16.64 \pm 2.90$ & $24.83 \pm 6.43^{*}$ & $17.36 \pm 6.15^{*}$ & 0.028 \\
PON-1 & $34.45 \pm 15.9$ & $51.52 \pm 17.2^{*}$ & $21.63 \pm 11.8^{\&}$ & 0.036 \\
CAT & $5724.6 \pm 873.9$ & $4355.9 \pm 548.2^{*}$ & $4383.2 \pm 419.1 *$ & 0.013 \\
\hline
\end{tabular}

TBARS $-\mathrm{nmol} / \mathrm{mg}$ protein, GST $-\mathrm{mIU} / \mathrm{mg}$ protein, SOD $-\mathrm{U} / \mathrm{mg}$ protein, $\mathrm{PON}-1$ $-\mathrm{mIU} / \mathrm{mg}$ protein, CAT $-\mathrm{IU} / \mathrm{mg}$ protein, ${ }^{*} \mathrm{p}<0.05$ when compared to Group $\mathrm{C} \&$ $\mathrm{p}<0.05$ when compared to Group IR

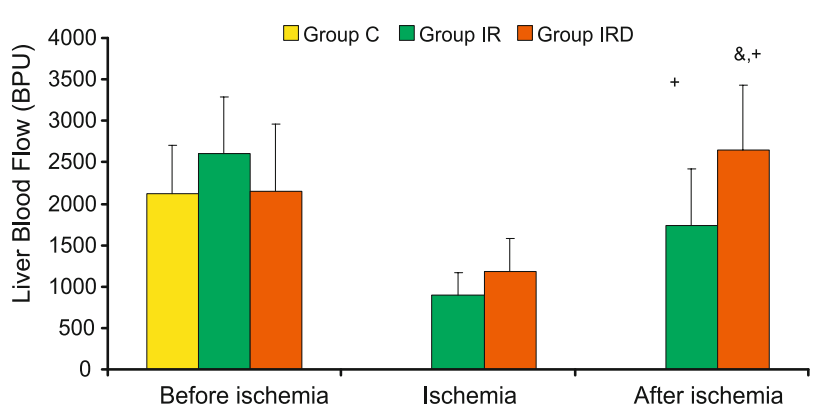

Fig. 2. Distributions of liver blood flow measurements in blood perfusion units (BPU). $\mathrm{p}<0.05$ when compared to group IR.

ischemia, liver blood flow in both groups were significantly increased compared to the period of ischemia (IR Group $p=0.017$, IRD Group $\mathrm{p}=0.012$ ) (Fig. 2).

\section{Discussion}

Hepatic I/R injury is defined as the prolongation and aggravation of ischemic tissue damage with reperfusion (26). Several cellular and molecular changes in hepatic I/R injury have been investigated in clinical and experimental studies. However, in this study, we have reported (for the first time, to our knowledge) the protective effect of dexmedetomidine on erythrocyte deformability alterations in experimental hepatic I/R injury model in the rat. Dexmedetomidine, which is a highly potent and selective $\alpha 2$-adrenoreceptor agonist, was administered before induction of ischemia, which resulted with decreased SOD activities and TBARS levels known to play a crucial role in the development of hepatic I/R injury.

Hepatic I/R injury induced by lipid peroxidation generates a complex variety of products. Many of these react with several protein products and DNA and cause local and systemic toxic and mutagenic effects (27). A major target site of lipid peroxidation is the cellular membrane which contains polyunsaturated fatty acids. Toxicity of partially reduced oxygen species arises from the peroxidation of polyunsaturated fatty acid of membrane phospholipids. The final event leading to structural and functional tissue damage is the loss of disintegration of cellular membrane. In hepatic I/R injury, this mechanism is exacerbated after reperfusion with microcirculatory derangements and altered mitochondrial functions (28).

On the other hand, p53 is a gene which regulates the cell cycle progression, modulates apoptosis and/or DNA repair in cellular responses to stress. While the $\mathrm{p} 53$ protein normally is short-lived and present at low levels in normal cells, in response to both genotoxic and nongenotoxic stresses it accumulates in the nucleus where it binds to specific DNA sequences and modulates DNA repair processes $(29,30)$. The arrest of cell cycle progression may provide time for the repair of DNA damage. If DNA does not repair completely, it stimulates apoptotic caspase cascades in cytoplasm and the cell kills itself. Furthermore, Heat Shock Protein 60 (HSP60) is a member of heat shock proteins which are responsible for preventing damage to proteins in response to high levels of heat. It is a mitochondrial chaperonin responsible for transportation and refolding of proteins from cytoplasm to mitochondrial matrix. Nowadays, dif- 
ferent studies suggest that this protein is involved in stress response, cancer, diabetes and some immunological disorders. Up-regulation of HSP60 production allows for the maintenance of different cellular processes in the cell especially during stressful time (31). In a study, it was shown that HSP's are playing an important role in the defensive mechanism against neurotoxicity elicited by free radical oxygen and nitrogen species produced in aging and neurodegenerative disorders (32). Different studies have shown that HSP60 are necessary for cellular survival under toxic and stressful circumstances (33). Four hours after reperfusion, liver transplant patients were shown to have significantly increased serum levels of HSP60 (34).

In our study, the fact that we detected that p53 was significantly upregulated in I/R group means that I/R process stimulates DNA damage. However, in $\mathrm{I} / \mathrm{R}+\mathrm{D}$ group it was shown that $\mathrm{p} 53$ was significantly downregulated, which means that dexmedetomidine has protective effects on I/R-related cell damage. At the same time, in $\mathrm{I} / \mathrm{R}+\mathrm{D}$ group we also detected a decrease in $\mathrm{p} 53$ expression/suppression profile which means that dexmedetomidine prevention has beneficial effects on cellular stress. Furthermore, the significant decrease in HSP60 expression in I/R+D group when compared to $\mathrm{I} / \mathrm{R}$ group also shows the beneficial effects of dexmedetomidine on cellular stress.

Free oxygen radicals have a marked mediator role in IR injuries of several organs, including the liver $(6,35,36)$. Some research suggests that antioxidant molecules may provide protection from $\mathrm{I} / \mathrm{R}$ injury $(6,7,37,38)$.

In our study, by measuring the liver tissue CAT, PON-1, SOD, GST activities and TBARS levels, we obtained information about hepatic I/R. PON enzyme shows antioxidant activity by protecting LDL from oxidation and neutralizing free radicals, including hydrogen peroxide (39-41).

Oxidative damage occurs when this equilibrium is disrupted. Increased lipid peroxidation is also one of the results of increased oxidative stress (42). It was reported that some parameters of erythrocyte functions and membrane integrity were impaired in increased lipid peroxidation in in vivo and in vitro studies (43). The products that arise due to lipid peroxidation associated with increased oxidative stress significantly affect membrane permeability and micro viscosity. Thus, the diminished deformability capacity and survival of erythrocytes are observed (44). SOD, CAT, and GSHPx are responsible for cellular antioxidant defense mechanisms. These enzymes eliminate superoxide anions and hydrogen peroxides, and prevent free radical production (45). SOD is the primary defensive enzyme against oxygen-derived free radical production and catalyses $\mathrm{H}_{2} \mathrm{O}_{2}$ conversion $\mathrm{O}_{2}^{-}$(46). Oxygen radicals generated in response to $\mathrm{I} / \mathrm{R}$ have been implicated in the micro vascular dysfunction and parenchymal cell injury of the intestine and liver $(47,48)$. The TBARS assay, which measures MDA, is a simple and easy-to-use method for assessment of the degree of injury attributable to the free radicals produced by ischemia/reperfusion, and is frequently used in laboratory (49). In this current study, increased TBARS levels were accompanied in hepatic I/R group. Dexmedetomidine treatment was also observed to be protective against increased TBARS production in hepatic I/R injury.

In this study, the decreased activity of PON, SOD, CAT activi- ties and TBARS levels in liver tissue support the protective effect of dexmedetomidine.

In conclusion, it was found that dexmedetomidine increased the antioxidant ability and decreased oxygen free radicals in the early period of hepatic IR injury in rats.

In conclusion, the results of this study clearly demonstrated that HSP60, p53 are significantly upregulated in experimental hepatic $\mathrm{I} / \mathrm{R}$ injury in the rat. The increased production of SOD, PON and TBARS, which causes lipid peroxidation and cellular membrane alterations may play an important role in alterations. However, it was observed that when given before induction of ischemia, dexmedetomidine has protective effects on these alterations in hepatic I/R injury. Other aspects of these findings including clinical significance and practical applications merit further experimental and clinical investigation.

\section{References}

1. Siriussawakul A, Zaky A, Lang JD. Role of nitric oxide in hepatic ischemia-reperfusion injury. World J Gastroenterol 2010; 16 (48): 6079-6086.

2. Alchera E, Dal Ponte C, Imarisio C, Albano E et al. Molecular mechanisms of liver preconditioning. World J Gastroenterol 2010; 16 (48): 6058-6067.

3. Yaylak F, Canbaz H, Caglikulekci M et al. Liver tissue inducible nitric oxide synthase (iNOS) expression and lipid peroxidation in experimental hepatic ischemia reperfusion injury stimulated with lipopolysaccharide: the role of aminoguanidine. J Surg Res 2008; 148 (2): 214-223.

4. Bedirli N, Ofluoglu E, Kerem M et al. Hepatic energy metabolism and the differential protective effects of sevoflurane and isoflurane anesthesia in a rat hepatic ischemia-reperfusion injury model. Anesth Analg 2008; 106 (3): 830-837.

5. Grisham MB, Granger DN. Free radicals: reactive metabolites of oxygen as mediators of postischemic reperfusion injury. In: Martson A, Bulkley GB, Fiddian-Green RG, Haglung U (Eds). Splanchnic ischemia and multiple organ failure. St. Louis: Mosby; 1989: 135-144.

6. Yildiz F, Coban S, Terzi A, Ates M, Aksoy N, Cakir H et al. Nigella sativa relieves the deleterious effects of ischemia reperfusion injury on liver. World J Gastroenterol 2008; 14: 5204-5209.

7. Shen SQ, Zhang Y, Xiang JJ, Xiong CL. Protective effect of curcumin against liver warm ischemia/reperfusion injury in rat model is associated with regulation of heat shock protein and antioxidant enzymes. World $\mathbf{J}$ Gastroenterol 2007; 13: 1953-1961.

8. Sener G, Tosun O, Sehirli AO, Kacma A, Arbak S, Ersoy Y et al. Melatonin and $\mathrm{N}$-acetylcysteine have beneficial effects during hepatic ischemia and reperfusion. Life Sci 2003; 72: 2707-2718.

9. Tarpey MM, Wink DA, Grisham MB. Methods for detection of reactive metabolites of oxygen and nitrogen: in vitro and in vivo considerations. Am J Physiol Regul Integr Comp Physiol 2004; 286: 431-444.

10. Grisham MB, Granger DN. Free radicals: reactive metabolites of oxygen as mediators of postischemic reperfusion injury. In: Martson A, Bulkley GB, Fiddian-Green RG, Haglung U (Eds). Splanchnic ischemia and multiple organ failure. St. Louis: Mosby; 1989: 135-144.

11. Levine AJ. p53, the cellular gatekeeper for growth and division. Cell 1997; 88: 323-331

12. McCutcheon CA, Orme RM, Scott DA et al. A comparison of dexmedetomidine versus conventional therapy for sedation and hemodynamic 


\section{0-684}

controlduring carotid endarterectomy performed under regional anesthesia. Anesth Analg 2006; 102: 668-675.

13. Ramsay MA, Luterman DL. Dexmedetomidine as a total intravenous anesthetic agent. Anesthesiology 2004; 101: 787-790.

14. Maier CM, Sun GH, Kunis DM et al. Neuroprotection by the Nmethyl-D-aspartate receptor antagonist CGP 40116: In vivo and in vitro studies. J Neurochem 1995; 65: 652-659.

15. Kocoglu H, Karaaslan K, Gonca E, Bozdogan O, Gulcu N. Preconditioning effects of dexmedetomidine on myocardial ischemia/reperfusion injury in rats. Curr Ther Res Clin Exp 2008; 69: 150-158.

16. Kocoglu H, Ozturk H, Ozturk $H$ et al. Effect of dexmedetomidine on ischemia-reperfusion injury in rat kidney: a histopathologic study. Ren Fail 2009; 31 (1): 70-74.

17. Hoffman WE, Kochs E, Werner C et al. Dexmedetomidine improves neurologic outcome from incomplete ischemia in the rat. Reversal by the alpha 2-adrenergic antagonist atipamezole. Anesthesiology 1991; 75: 328-332.

18. Snapir A, Posti J, Kentala E et al. Effects of low and high plasma concentrations of dexmedetomidine on myocardial perfusion and cardiac function in healthy male subjects. Anesthesiology 2006; 105: 902-910.

19. EngelhardK, WernerC,EberspächerEetal. The effect of the alpha 2-agonist dexmedetomidine and the N-methyl-D-aspartate antagonist S (+)-ketamine on the expression of apoptosis-regulating proteins after incomplete cerebral ischemia and reperfusion in rats. Anesth Analg 2003; 96 (2): 524-531.

20. Lowry O, Rosenbraugh N, Farr L, Randall R. Protein measurement with folin phenol reagent. J Biol Chem 1951; 182: 265-275.

21. Van Ye TM, Roza AM, Pieper GM, Henderson J Jr, Johnson JP, Adams MB. Inhibition of intestinal lipid peroxidation does not minimize morphological damage. J Surg Res 1993; 55: 553-558.

22. Durak I, Canbolat O, Kavutcu M, Öztürk HS, Yurtarslani Z. Activities of total, cytoplasmic and mihochondrial superoxide dismutase enzymes in sera and pleural fluids from patient with lung cancer. J Clin Lab Anal 1996; 10: 17-20.

23. Aebi H. Catalase. In: Bergmeyer HU (Ed. Methods of Enzymatic Analysis, Academic Press, New York and London, 1974; pp. 673-677.

24. Habig WH, Pabst MJ, Jakoby WB. Glutathione S-transferases. The first enzymatic step in mercapturic acid formation. J Biol Chem 1974; 249: 7130-7139.

25. Fernando Daniel Brites, Julia'n Verona, Laura Ester Schreier et al. Paraoxonase 1 and platelet-activating factor acetylhydrolase activities in patients with low HDL-cholesterol levels with or without primary hypertriglyceridemia. Arch Med Res 2004; 35 (3): 235-240.

26. Jaeschke H, Leamsters JJ. Apoptosis versus oncotic necrosis in hepatic ischemia/reperfusion injury. Gastroenterology 2003; 125: 1246-1257.

27. Marnett LJ. Lipid peroxidation - DNA damage by malondialdehyde. Mutat Res 1999; 424: 83-95.

28. Giakoustidis D, Papageorgiou G, Iliadis $S$ et al. The protective effect of alpha-tocopherol and $\mathrm{GdCl} 3$ against hepatic ischemia/ reperfusion injury. Surg Today 2006; 36: 450-456.

29. Hanawalt PC. Controlling the efficiency of excision repair. Mutat Res 2001; 485 (1): 3-13.

30. Smith ML, Seo YR. p53 regulation of DNA excision repair pathways. Mutagenesis 2002; 17 (2): 149-156.

31. Vargas-Parada L, Solís CF, Laclette JP. Heat shock and stress response of Taenia solium and T. crassiceps (Cestoda). Parasitology 2001; 122 (Pt 5): 583-858.
32. Calabrese V, Mancuso C, Ravagna A, Perluigi M, Cini C, De Marco C, Butterfield DA, Stella AM. In vivo induction of heat shock proteins in the substantia nigra following L-DOPA administration is associated with increased activity of mitochondrial complex I and nitrosative stress in rats: regulation by glutathione redox state. J Neurochem 2007; 101 (3): 709-717.

33. Rossi MR, Somji S, Garrett SH, Sens MA, Nath J, Sens DA. Expression of hsp 27, hsp 60, hsc 70, and hsp 70 stress response genes in cultured human urothelial cells (UROtsa) exposed to lethal and sublethal concentrations of sodium arsenite. Environ Health Perspect 2002; 110 (12): 1225-1232.

34. Faybik P, Wachauer D, Hetz H, Bachleitner T, Steltzer H, Schett G, Krenn CG. Perioperative kinetics of heat shock protein 60 in serum during orthotopic liver transplantation. Transplant Proc 2004; 36 (5): 1469-1472.

35. Yuan GJ, Ma JC, Gong ZJ, Sun XM, Zheng SH, Li X. Modulation of liver oxidant-antioxidant system by ischemic preconditioning during ische$\mathrm{mia} /$ reperfusion injury in rats. World J Gastroenterol 2005; 11: 1825-1828.

36. Zhang SJ, Shi JH, Tang Z, Wu Y, Chen S. Protective effects of glycine pretreatment on brain-death donor liver. Hepatobiliary Pancreat Dis Int 2005; 4: 37-40.

37. Hassan-Khabbar S, Cottart CH, Wendum D, Vibert F, Clot JP, Savouret JF et al. Postischemic treatment by trans-resveratrol in rat liver ischemiareperfusion: a possible strategy in liver surgery. Liver Transpl 2008; 14: 451-459.

38. Polat KY, Aydinli B, Polat O, Aydin U, Yazici P, Ozturk G et al. The protective effect of aprotinin and alpha-tocopherol on ischemia-reperfusion injury of the rat liver. Transplant Proc 2008; 40: 63-68.

39. Celik M, Gulcu F, Ozan G, Gursu MF. Paraoxonase and arylesterase activity levels in workers exposed to organic solvents. Turk J Biochem 2005; 30: 194-199.

40. Yildirim A, Aslan S, Ocak T, Yildirim S, Kara F, Sahin YN. Serum paraoxonase/arylesterase activities and malondialdehyde levels in trauma patients. Eurasian J Med 2007; 39: 85-88.

41. Memisogullari R, Orhan N. Paraoxonase and cancer. Konuralp Tip Dergisi 2010; 2: 22-26.

42. Therond P, Bonnefont-Rousselot D, Spraul AD et al. Biomarkers of oxidative stress: an analytical approach. Curr Opin Clin Nutr Metab Care 2000; 3: 373-384.

43. Kuypers FA. Red cell membrane damage. J Heart Valve Dis 1998; 7: $387-395$.

44. Sivilotti ML. Oxidant stress and haemolysis of the human erythrocyte. Toxicol Rev 2004; 23: 169-188.

45. Mates JM, Perez-Gomez C, Castro IN. Antioxidant enzymes and human disease. Clin Biochem 1999; 32 (8): 595- 603.

46. Yerer MB, Yapislar H, Aydogan S et al. Lipid peroxidation and deformability of red blood cells in experimental sepsis in rats: The protective effects of melatonin. Clin Hemorheol Microcirc 2004; 30: 77-82.

47. Johnson F, Giulivi C. Superoxide dismutases and their impact upon human health. Mol Aspects Med 2005; 26: 340-352.

48. Yagmurdur MC, Ozdemir A, Topaloglu S et al. Effects of alpha tocopherol and verapamil on liver and small bowel following mesenteric ischemia-reperfusion. Turk J Gastroenterol 2002; 13: 40-46.

49. Granger DN, Korthuis RJ. Physiologic mechanisms of postischemic tissue injury. Annu Rev Physiol 1995; 57: 311-332.

Received April 19, 2013. Accepted March 28, 2014. 